\title{
DEMONSTRATION OF USING LOW CARBON PRECAST CONCRETE PRODUCTS FOR AN ENERGY EFFICIENT BUILT ENVIRONMENT
}

\author{
T.E. McGrath ${ }^{(1)}$, J. Kwasny ${ }^{(1)}$, T.A. Aiken ${ }^{(1)}$, S. Cox ${ }^{(1)}$, M. Soutsos ${ }^{(1)}$, J.F. Chen ${ }^{(1)}$, \\ J. Mariotti ${ }^{(1)}$,W. Sha, ${ }^{(1)}$, R. Correia ${ }^{(2)}$ \\ (1) School of Natural \& Built Environment, Queen's University Belfast, Northern \\ Ireland \\ ${ }^{(2)}$ Creagh Concrete Ltd., Toomebridge, Northern Ireland.
}

\begin{abstract}
The production of Portland cement is well acknowledged as having a significant impact on the environment, accounting for $8 \%$ of global $\mathrm{CO}_{2}$ emissions (4bn tonnes per annum). Concrete is the most widely used man-made material in the world and therefore has a vast potential to absorb high volumes of waste and by-product materials. These materials can act as partial replacements, i.e. supplementary cementitious materials, or total replacements and be the cement-like precursors for geopolymer concretes. The LowCoPreCon project brings together academic and industrial partners from the UK and Malaysia with the aim of identifying available waste streams with which to manufacture geopolymer concretes on a commercial scale.

Initial laboratory work was conducted by academic partners to design geopolymer concretes that had both optimum strength and workability. These mixes were then used in factory trials to successfully cast structural elements, including building blocks, wall slabs and staircases. To determine the potential environmental benefits of geopolymer concrete, a detailed life cycle assessment will be conducted. Two demonstration projects using the novel material will be constructed in Malaysia; a domestic building and a FlexiArch bridge.
\end{abstract}

Keywords: Precast concrete, low carbon, energy efficiency, supplementary cementitious materials.

\section{INTRODUCTION}

In October 2014 the EU Leaders agreed a target of $40 \%$ reduction in greenhouse gas (GHG) emissions by 2030 (based on 1990 levels) (European Commission 2014). The Eleventh Malaysian plan has set the goal of reducing Malaysia's GHG emission intensity of GDP by 40\% (compared to 2005 levels) by 2020 (The Economic Planning Unit 2016). These ambitious targets reflect the global commitment to reducing GHG emissions. Portland cement production produces 5-8\% of global $\mathrm{CO}_{2}$ emissions and 
contributes significantly to the $40 \%$ of total GHGs attributed to the built environment (Provis \& Van Deventer 2014). The environmental impact of cement is well acknowledged with significant emissions from three distinct areas; emissions produced as the raw materials are calcined at high temperatures to form clinker, emissions associated with fuel combustion in the cement kiln and the emissions associated with energy used to operate the cement plant (Heede \& Belie 2012). The calcination process is the largest contributor of these three areas, and is responsible for approximately $50 \%$ of cement $\mathrm{CO}_{2}$ emissions. Calcination requires the burning of the calcium carbonate, forming calcium oxide and carbon dioxide. So whilst there is potential to reduce environmental emissions associated with fuel and energy use, the nature of the calcination process means that potential reduction of the environmental impact of cement is constrained.

Alkali activated concrete (AAC) or geopolymer concrete has emerged as a promising alternative to traditional Portland cement based concrete. Geopolymer is an umbrella term which refers to a wide range of synthetic aluminosilicate polymeric materials. Geopolymer materials can be produced from a range of natural and synthetic pozzolanic binder materials, activated with alkaline solutions such as sodium hydroxide and sodium silicate. Geopolymers can act as "cementless" binders to replace Portland cement pastes in concrete products. Previous studies comparing geopolymer materials to Portland cement products have reported a wide range of potential reduction in $\mathrm{CO}_{2}$ emissions of between $30-80 \%$, (Tempest et al., 2009, Weizsacker et al., 2009; McLellan et al., 2011; Stengel et al., 2009).

The LowCoPreCon project aims to develop geopolymer products from locally available waste streams. The project is supported by the Newton-Ungku Omar Coordination Fund which facilitates innovative research between the UK and Malaysia. The work brings together industrial and academic partners and is jointly funded by Innovate UK and MIGHT (Malaysian Industry Government Group for High Technology). The project team consists of academic and industrial partners in both the UK and Malaysia. In the UK, Queen's University is the project lead with industrial input provided by Creagh Concrete Ltd and Macrete Ltd. In Malaysia, University of Malaya and Monash University are the academic partners with industrial input provided by Sunway and Ikhmas Jaya Group Berhad. This paper will provide an overview and summary of the work that is being undertaken, from identification of suitable waste streams, laboratory and factory scale trials, the planned demonstration projects and assessing the environmental and socio-economic impacts of these novel materials.

\section{SUITABLE WASTE STREAMS FOR GEOPOLYMER CONCRETE}

The construction industry is uniquely placed to be able to incorporate high-volumes of waste materials or by-products, for example the annual cement production in GB is in the region of 10 million tonnes and in Malaysia is over 20 million tonnes (Department of Statistics 2017). Whilst geopolymer concretes have been used in applications 
world-wide, the use of expensive chemical activators has made their use cost prohibitive. Geopolymer concrete has lower $\mathrm{CO}_{2}$ emissions when compared to conventional concrete, however other studies which examine a wider range of environmental impact categories show that the activators are the source of significant impact (Habert et al. 2011; Habert \& Ouellet-Plamondon 2016). The initial focus of the project was the identification and characterisation of suitable local waste aluminasilicate rich ash and alkali activator sources that were available locally and in sufficient quantities. Detailed microstructural characterisation was carried out to assess the suitability of these materials as geopolymer components.

Fly ash (FA) is produced by power generating stations during the production of electricity using coal as the fuel. Finely powdered (pulverized) coal is mixed with heated air and burned. The resultant ash is transported by the exhaust gases and recovered as 'fly ash' with fine particles. Over 22Mt of coal is consumed annually in Malaysia providing a readily exploitable source of over 3Mt of FA. While FA is an established additive to cement and concrete manufacture, typically $2 \mathrm{Mt}$ of FA is still landfilled annually in the UK and there is an excess of 50Mt of FA stockpiled in the UK (Cooke 2018). These stockpiles of FA are usually stored in lagoons or ash ponds. Even in circumstances where these lagoons have liners, seepage, spills and overflows may be hazardous to the groundwater and subsurface soil.

Ground granulated blast-furnace slag (GGBS) is a by-product from the manufacturing of iron and steel and it is available in both the UK and Malaysia. In iron and steel production blast-furnaces are fed with carefully controlled mixtures of iron-ore, coke and limestone, with temperatures of about $1500^{\circ} \mathrm{C}$. Once the metal has been separated from the ore the material that remains is referred to as slag. The slag is rapidly quenched in large quantities of water. The process of quenching improves the cementitious properties and produces granules similar to coarse sand particles. The 'granulated slag' is dried and ground to a fine powder that is called GGBS.

Whilst a number of alkali waste activator sources were investigated the most promising material identified in the UK was powdered glass cullet (GC) particles. According to the most recent waste statistics (Department for Environment Food \& Rural Affairs 2016), there was more than 2 million tonnes of glass waste produced in the UK, the majority of which came from household waste. Of this glass waste, the vast majority was recycled, with the remainder deposited in landfill or used as backfill. During the recycling process of the glass, the glass is broken down by impact crushers and sieved. Ultra-fine powered glass cullet particles are gathered during the screening phase and cannot be reintroduced to the recycling process. As a result this material is usually landfilled. Extensive experimental work has been undertaken to use this material as the silicate source required for the alkali activation in the geopolymer system as described in Vinai and Soutsos, (2019). The fine GC powder is combined with sodium hydroxide in mass proportions of $48 \% / 52 \%$ and combined with water to make a paste. The mixture is then heated in a conventional oven, at a temperature of between $150^{\circ}$ to $330^{\circ} \mathrm{C}$, for a period of approximately 90 minutes. This produces a powdered activator source, which has a comparable price, with the potential to be cheaper than 
conventional Portland cement concretes with equivalent strengths. In Malaysia the silicate sources being investigated include rice husk ash (the ash residue after rice husk is burned) and coastal sand.

\section{GEOPOLYMER LABORATORY TRIALS}

As part of the LowCoPreCon project, extensive laboratory trials were conducted in Queen's University Belfast. The FA was obtained from the 560MW capacity coal and oil burning Kilroot power station, Northern Ireland. GGBS was sourced from ECOCEM in Dublin, Ireland. The GC was sourced from a glass recycling facility in Tyrone, Northern Ireland. The alkali dosage $(\mathrm{M}+)$ used in the geopolymer concretes is defined as the percentage mass ratio of the total sodium oxide $\left(\mathrm{Na}_{2} \mathrm{O}\right)$ in the activating solution to the binder. The alkali modulus (AM) is defined as the mass ratio of sodium oxide to silica in the activating solution (Rafeet et al. 2017). Initially the materials were trialled individually at a mortar level and compared with laboratory controls. In the case of the GC based activator, the compressive strength values compared well with commercial silicates. For example, in a 60/40 FA/GGBS mortar $(\mathrm{AM}=1.0$ and $\mathrm{M}=+7.5)$ the $\mathrm{GC}$ activator achieved a 28 day compressive strength values of $45 \mathrm{MPa}$ compared with $40 \mathrm{MPa}$ using commercial silicates. Likewise the Kilroot fly ash was compared with a laboratory control fly ash (Drax) achieving comparable compressive strength values of up to $70 \mathrm{MPa}$ at 28 days with curing at $70^{\circ} \mathrm{C}$. Laboratory work was then carried out to scale these mortar mixes to concrete mixes suitable to manufacture precast units. A range of parameters were tested; including paste volume, water/solid ratio and M+/AM varied, to develop a mix that could be used during the factory trials. The required strength and workability properties were specified by the industrial partner, Creagh Concrete Ltd and are outlined below:

- Mix was required to have good workability - a high slump value after 30 minutes was required to ensure the mix did not set before batching, casting and finishing the products had been completed.

- Early age strength development - a compressive strength of $15 \mathrm{MPa}$ after 16 hours, which allows for the product to be demoulded and lifted was required. Given the high volume nature of precast concrete manufacturing, this is a typical production process requirement.

- Characteristic compressive strength values of between 40 - 50MPa after 28 days were required for the manufactured precast elements.

Two sets of mixes were investigated for the trial, 100\% FA mix (which would require elevated curing temperature) and a FA/GGBS blend (which could be cured at ambient temperature). Maintaining workability of the FA/GGBS mix proved to be difficult and a number of admixtures were trialled with limited effect. To reduce the risk of "flash setting", paste volume and water/solid ratios were varied.

A geopolymer block mix was also developed and trialled in the laboratory. A specially designed rig that incorporates a compaction hammer and vibrating plate was used to replicate the manufacturing process on site. Liaising with Creagh, targeted 
requirements for the blocks were defined. The target compressive strength for conventional concrete blocks is $3 \mathrm{MPa}$ at 4 days, to allow for strapping and moving blocks, and 7MPa strength at 28 days. Similar laboratory trials, using FA and silicate sources manufactured from the rice husk ash and coastal sand are being undertaken in the University of Malaya and Monash University to facilitate Malaysian factory trials, that are due to commence early 2019.

\section{GEOPOLYMER FACTORY TRIALS}

In May and June 2018, factory scale trials using geopolymer concretes were successfully carried out by Creagh Concrete, Toomebridge. Effective transfer of knowledge and sharing of best practice were an important requirement of the funding bodies. To facilitate an effective exchange, Malaysian partner visits were scheduled to coincide with factory trials in the UK and meetings hosted at the factory site.

Overall 8 batches were manufactured, producing over 20 tonnes of geopolymer concrete. This material was used to manufacture precast specimens including walls, slabs, stairs and building blocks. For the precast elements two mixes were selected to progress onwards for the factory trials $100 \%$ FA and 30/70 FA/GGBS mix. The 100\% FA products were activated with commercial silicates and the 30/70 FA/GGBS mix was activated using the GC activator. To cure the $100 \% \mathrm{FA}$ mix an elevated temperature (up to $70^{\circ} \mathrm{C}$ ) was required. A heating chamber was fabricated using a structural steel frame and insulation board. The heat source used was a $6 \mathrm{~kW}$ sauna heater. The size of the chamber manufactured was $3.4 \times 2.4 \mathrm{~m} \times 1.4 \mathrm{~m}$ and had hooks installed at the top, so it could be moved by fork lift and positioned on heated curing beds, as shown in Figure 1.

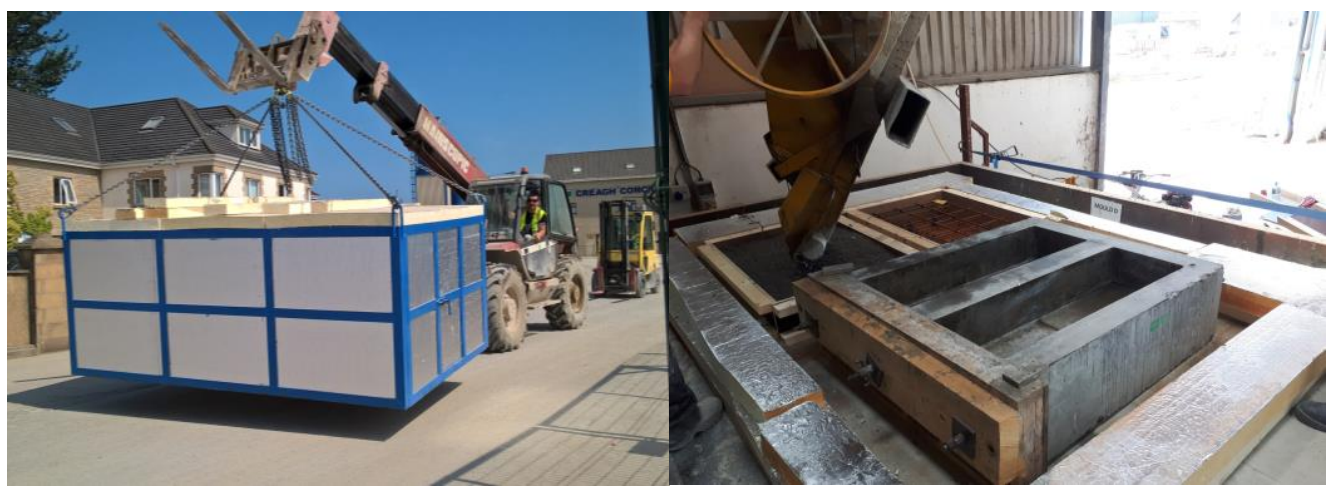

Figure 1. Curing chamber constructed for factory trials (left) and pouring of $100 \%$ FA specimens (right).

Both mixes were found to be sufficiently workable for the factory setting with the $30 / 70$ FA/GGBS mixes having slump values of between $220-260 \mathrm{~mm}$ and the $100 \%$ FA mixes having table flow values of between $720-750 \mathrm{~mm}$ after approximately 30 minutes. 
Of crucial importance for any precast concrete product is the early age of $15 \mathrm{MPa}$ compressive strength which is needed to allow for lifting and demoulding of the specimen after approximately 16 hours. The 30/70 FA/GGBS trialled on site achieved an impressive 22MPa after 16 hours. After 28 days the 30/70 GA/GGBS blend achieved compressive strength values up to $48 \mathrm{MPa}$. Given that the $100 \%$ FA mix required elevated temperature that could not be fully guaranteed during the trial, it was decided to leave specimens for a full 24 hours before compression tests were carried out. After 24 hours, the samples achieved $18 \mathrm{MPa}$. The 28 day compressive strength result was $29 \mathrm{MPa}$. However, given that the 7 day compressive strength had measured at $34 \mathrm{MPa}$ the low result at 28 days. Some cracking was visible on the $100 \%$ FA mix panels which could possibly be linked to poor heat circulation within the chamber with a $15^{\circ} \mathrm{C}$ temperature differential between the top and bottom of the chamber.

For the block trials a 30/70 FA/GGBS mix was activated with commercial silicates. A conventional Portland cement (PC) mix was cast at the same time to act as a control mix. The first batch manufactured was too dry and while blocks were cast, they were not successful. For the next two batches, additional water was added. Two sets of blocks were cast from each batch. One set of each batch was covered with timber boxes and the other set remained uncovered. The blocks that remained uncovered had a higher level of efflorescence than the covered blocks. Despite the efflorescence there is little difference between the compressive strength values of the covered vs. uncovered mixes. Both mixes achieved above the minimum 4-day strength of 3MPa. For the 28-day strength, for both covered and uncovered specimens, one mix achieved just below the requirement of $7 \mathrm{MPa}$, with $6 \mathrm{MPa}$ whilst the other mix achieved $10 \mathrm{MPa}$. This disparity between strength values may be attributed to the water content. The first batch had a drier consistency and the water content was corrected for the subsequent batch, which performed better.

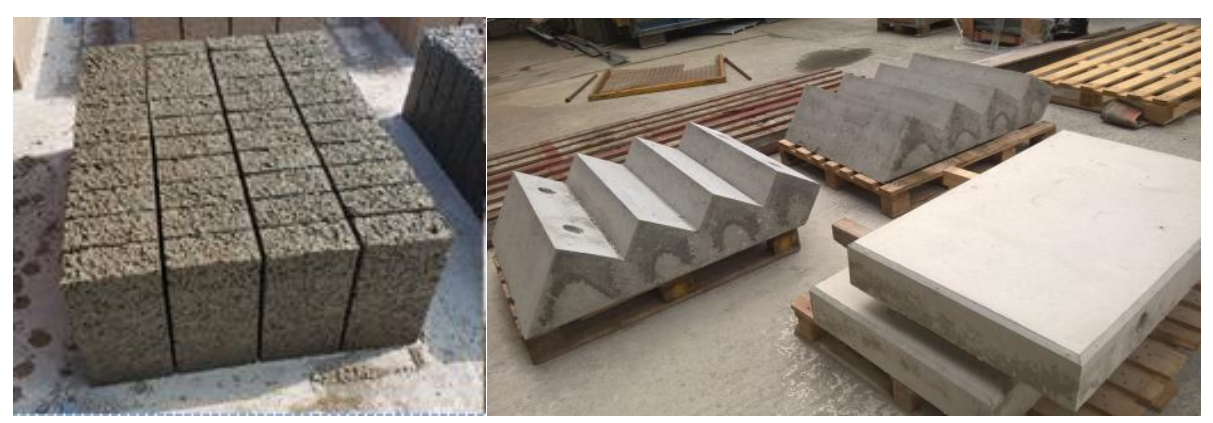

Figure 2. Geopolymer specimens manufactured in Creagh Concrete Ltd.

\section{GEOPOLYMER DEMONSTRATION PROJECTS IN MALAYSIA}

There will be two demonstration projects constructed using geopolymer concrete in Malaysia in 2019 and are shown in Figure 3. 

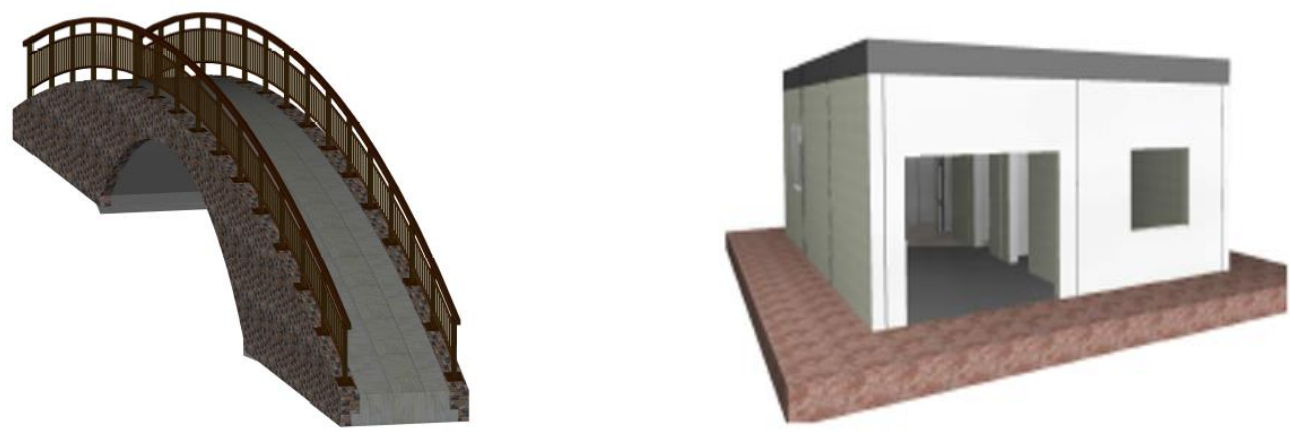

Figure 3. Proposed demonstration projects - FlexiArch (left) and precast demonstration dwelling (right).

The first demonstration project is Macrete designed FlexiArch bridge system, which will be used to construct a pedestrian bridge on the campus of University of Malaya in Kuala Lumpur. Sunway will be producing the bridge components using the geopolymer mixes developed at the University of Malaya and Monash University. Ikhmas Jaya Group Berhad will be carrying out the necessary geotechnical surveys, groundwork and constructing the bridge on the campus.

The second demonstration project is a low cost precast residential dwelling. The dwelling will be cast and constructed in a Sunway factory site in Batang Kali, Selangor. The dwelling has been designed to allow for flexibility of use in the living space, with rooms divided by non-structural internal partitions. This would allow the suppliers of such units to create a more diverse range of dwellings that are adaptable to the changing needs of householders.

\section{SUSTAINABILITY OF THE DEMONSTRATION DWELLING: LIFE CYCLE ASSESSMENT AND STAKEHOLDER ENGAGEMENT}

Life cycle assessment (LCA), is an internationally standardised framework can be used to quantify and compare the environmental impacts of products or processes (BS EN ISO 14040 2006). All products or processes have various stages in their life cycle and during each of these stages, energy and resources are consumed and emissions to the environment and wastes are produced. To ensure a fair and accurate comparison between products or processes, the quantified function of the item is taken into consideration. Within the LCA framework this is done by defining a "functional unit". In previous LCAs of the built environment in Malaysia the functional unit chosen has been per metre squared of habitable space (Jia Wen et al, 2015; Abd Rashid et al, 2017). This unit allows fair comparison between the significant difference in size of the buildings, expressing the environmental impact and energy consumption per metre squared. In the LowCoPreCon project the functional unit will be per metre square, to quantify and compare the environmental impact of FA precast 
concrete products utilised in the demonstration building and an equivalent PC residential building for a Malaysian context.

The system boundary, which outlines which stages of the product life cycle will be included in calculating the environmental impact, will be set to include a cradle to grave analysis. As such the environmental impact of the whole life of the structural elements of both the FA precast and equivalent PC residential buildings will be considered. This will include the extraction of raw materials, manufacturing of components, transportation, operation of the building and end-of-life of structures such as how the item will be disposed/reused/recycled. Primary data that will be gathered will include, quantities of materials used, haulage distances of materials, energy consumed in batching /curing products manufacturing of the geopolymer products in Malaysia. Secondary data sources including SIRIM MY-LCID (Malaysia Life Cycle Inventory Database) and Eco-Invent database will be used to complete the inventory analysis (SIRIM 2018). One of the challenges associated with the inventory stage is allocating environmental impact when a system produces more than one product or a waste that has a potential use. Both FA and GGBS would have been previously considered as wastes with little to none of the environmental impact assigned to them. However under the most recent Waste Framework Directive (Directive 2008/98/EC 2008), these items are now classified as «by-products ». Economic allocation is subject to is high variability due to price instability (Chen et al. 2010; Van de Heede \& De Belie 2012), whilst mass allocation allows for greater stability.

Both buildings will have an assumed operational life span of 50 years. The operational energy used throughout the life span of the building will be calculated using the dynamic energy simulation software Integrated Environmental Solutions - Virtual Environment (IES-VE). A significant driver of energy use in buildings are the temperature and relative humidity levels which are determined by the occupant. With limited literature values to indicate what typical levels would be in domestic buildings, a survey of internal temperature and relative humidity was conducted. Monitoring devices (USB OM-EL-2 type) were installed in the bedroom and living room in four domestic properties. The findings of this survey will help improve the accuracy of the operational modelling.

The end-of-life modelling will consider the current and likely future methods in which waste is recycled/reused or landfilled. The most recently available statistics show that the majority (60\%) of construction and demolition waste is dumped on private land or illegally landfilled (PEMANDU 2015). The Government aims to reduce to zero illegal dumping by the year 2020 .

The socio-economic impact of the use of geopolymer materials and novel construction methods of the demonstration dwelling will be assessed through engagement with stakeholders pre- and post- construction. To facilitate adoption of these products in a wider market, it is necessary to engage with stakeholders to identify their expectations and needs for the design and construction of their dwelling. 
To gather this information, participatory and interactive focus groups were developed. A short questionnaire gathered qualitative and quantitative information from the participants under the six following headings:

A) Socio-economic profile

B) Environmental problems (awareness and knowledge)

C) Materials and construction models

D) Design goals (Current dwelling) and design goals (New dwelling)

E) Prioritizing areas within the unit

F) Potential changes to project

G) Flexibility of the unit

The questionnaire was written in English and translated into the local language, Bahasa Melayu. To mitigate the risk of poor engagement due to lack of comprehension or language barriers interactive materials and props (cardboard scale models (1:50) of the demonstration dwelling and samples of gepolymer concrete) were a central part of the focus groups. Participants could interact with the model and materials and consult on potential design options and variations that would best suit their lifestyle and family needs. Overall 70 individuals took part in the focus groups that were held in six lowcost housing neighbourhoods in Kuala Lumpur in October 2018. The information gathered during these focus groups will help inform future design iterations of the dwelling and what information related to the geopolymer material is relevant and should be provided to potential future occupants.

\section{CONCLUSIONS}

Successful completion of large scale factory trials using a variety of waste materials to manufacture precast concrete units with geopolymer concrete have demonstrated the vast potential of this material to utilise substantial quantities of waste materials. Key lessons learned thus far in the project is the refinement of mixes at lab scale that are optimal for workability and early age strength development This allows for demoulding and lifting of the specimens as per the usual factory schedule, improving the likelihood of adoption of geopolymer mixes. The next focus for the LowCoPreCon project is to investigate the long term durability of the developed geopolymer materials, including sulphate resistance, freeze thaw and reinforcement corrosion. Similar laboratory trials are also being undertaken in Malaysia, with Malaysian factory trials due to commence in early 2019.

Concurrently, work is ongoing to collect inventory data to complete a detailed LCA of the demonstration dwelling to be constructed by Sunway in Malaysia and feedback is being gathered from participatory workshops in Malaysia to enhance understanding and improve prototyping of precast dwellings constructed from geopolymer concrete. Upon completion of the project, two innovative demonstration projects will have been constructed in Malaysia with research disseminated amongst key stakeholders including academic, policy and construction audiences. 


\section{ACKNOWLEDGEMENTS}

Authors gratefully acknowledge the funding provided by the Newton-Ungku Omar Fund, supported by Innovate UK and Malaysian Industry-Government Group for High Technology (MIGHT), for LowCoPreCon, Low Carbon Footprint Precast Concrete products for an energy efficient built environment, UKRI Project Ref. 102721.

\section{REFERENCES}

Abd Rashid, A., Idris, J. \& Yusoff, S., 2017. Environmental Impact Analysis on Residential Building in Malaysia Using Life Cycle Assessment. Sustainability, 9(3), p.329. Available at: http://www.mdpi.com/2071-1050/9/3/329.

BS EN ISO 14040, 2006. Environmental Management - Life Cycle Assessment Principles and Framework,

Cooke, N., 2018. As fly ash supplies dwindle what should the construction industry do? Institution of Civil Engineers. Available at: https://www.ice.org.uk/newsand-insight/the-civil-engineer/may-2018/fly-ash-supplied-dwindle.

Department for Environment Food \& Rural Affairs, 2016. UK Statistics on Waste. , (December), pp.1-24. Available at: http://www.statisticsauthority.gov.uk/assessment/code-of-practice/index.html.

Department of Statistics, M., 2017. Statistics yearbook of Malaysia 1st Editio., Putrajaya, Malaysia: Jabatan Perangkaan Malaysia.

European Commission, 2014. EU leaders agree 2030 climate and energy goals. Climate Action News. Available at: https://ec.europa.eu/clima/news/articles/news_2014102401_en.

Habert, G., D’Espinose De Lacaillerie, J.B. \& Roussel, N., 2011. An environmental evaluation of geopolymer based concrete production: Reviewing current research trends. Journal of Cleaner Production, 19(11), pp.1229-1238. Available at: http://dx.doi.org/10.1016/j.jclepro.2011.03.012.

Habert, G. \& Ouellet-Plamondon, C., 2016. Recent update on the environmental impact of geopolymers. RILEM Technical Letters, 1, pp.17-23.

Heede, P. Van Den \& Belie, N. De, 2012. Cement \& Concrete Composites Environmental impact and life cycle assessment ( LCA ) of traditional and ' green ' concretes : Literature review and theoretical calculations. Cement and Concrete Composites, 34(4), pp.431-442. Available at: http://dx.doi.org/10.1016/j.cemconcomp.2012.01.004.

Jia Wen, T., Chin Siong, H. \& Noor, Z.Z., 2015. Assessment of embodied energy and global warming potential of building construction using life cycle analysis approach: Case studies of residential buildings in Iskandar Malaysia. Energy and Buildings, 93, pp.295-302. Available at: http://dx.doi.org/10.1016/j.enbuild.2014.12.002.

McLellan, B.C., Williams, R.P., Lay, J., Van Riessen, A. \& Corder, G.D., 2011. Costs and carbon emissions for geopolymer pastes in comparison to ordinary 
portland cement. Journal of Cleaner Production, 19(9-10), pp.1080-1090.

Available at: http://dx.doi.org/10.1016/j.jclepro.2011.02.010.

PEMANDU, 2015. Solid Waste Management Lab 2015. 27th May - 12th June SWM Lab 2015, (June). Available at:

http://www.kpkt.gov.my/resources/index/user_1/Attachments/hebahan_slider/sl aid_dapatan_makmal.pdf.

Provis, J.L. \& Van Deventer, J.S.J., 2014. Alkali avtivated materials, Netherlands: Springer. Available at:

http://www.springer.com/engineering/civil+engineering/book/978-94-0077671-5.

Rafeet, A., Vinai, R., Soutsos, M. \& Sha, W., 2017. Guidelines for mix proportioning of fly ash/GGBS based alkali activated concretes. Construction and Building Materials, 147, pp.130-142. Available at: http://dx.doi.org/10.1016/j.conbuildmat.2017.04.036.

SIRIM, 2018. Malaysia Life Cycle Inventory Database. Available at: http://lcamalaysia.sirim.my/ [Accessed March 23, 2018].

Stengel, T., Reger, T., Heinz, D., 2009. Life Cycle Assessment of Geopolymer Concrete - What is the Environmental Benefit? In: Concrete Solutions 09. Concrete Instiitute of Australia, Luna Park, Sydney.

Tempest, B., Sanusi, O., Gergely, J., Ogunro, V. \& Weggel, D., 2009. Compressive Strength and Embodied Energy Optimization of Fly Ash Based Geopolymer Concrete. 2009 World of Coal Ash (WOCA) Conference, pp.1-17. Available at: http://www.flyash.info/2009/045-tempest2009.pdf.

The Economic Planning Unit, P.M.D., 2016. Eleventh Malaysia Plan 2016-2020. Available at: http://epu.gov.my/en/rmk/eleventh-malaysia-plan-2016-2020.

Vinai, R. \& Soutsos, M., 2019. Production of sodium silicate powder from waste glass cullet for alkali activation of alternative binders. Cement and Concrete Research, 116(November 2018), pp.45-56. Available at: https://doi.org/10.1016/j.cemconres.2018.11.008.

Weizsacker, E. Von, Hargroves, K., Smith, M., Desha, C. \& Stasinopoulos, P., 2009. Factor Five: Transforming the Global Economy through 80\% Improvements in Resource Productivity, London: Earthscan/Routledge. Available at: https://eprints.qut.edu.au/70173/. 